\title{
A Critical Understanding of English Language Provision in Australia
}

\author{
Jianna Qiu',a, $\mathrm{Ke} \mathrm{Xu}^{2, \mathrm{~b}}{ }^{*}$ \\ ${ }^{1}$ School of Foreign Languages, Quanzhou Normal University, Quanzhou, Fujian, China \\ ${ }^{2}$ School of Physical Education, Quanzhou Normal University, Quanzhou, Fujian, China \\ aqiujianna@163.com, bxk7367@aliyun.com
}

\begin{abstract}
Keywords: English, Provision, Australia.
Abstract. This paper revolves around English in the local and global contexts, demonstrating an insightful investigation into English language provision in Australia through a variety of topics ranging from general purposes to specific programs, with the aim of achieving high levels of understanding and intercultural communication.
\end{abstract}

\section{Introduction}

In the current context of globalization, English plays an indispensable role on the international stage, acting as an international language. Based on the intercultural communication, the spread of English is fast and wide with the growth of world Englishes, and at the same time is beneficial for the development of English language from the linguistic perspective. In practice, the popularity and importance of English develop with the increase of its status which is irreplaceable at present and in the future, and is demonstrated in various forms throughout the world, such as the College English Test (CET) in China and the International English Language Testing System (IELTS). However, the key point lies in that, it is in the English language industry involving a series of educational sectors such as the Technical and Further Education (TAFE) in Australia that the English language leaning and teaching is practiced. As a result, besides a brief introduction to different contexts and purposes for English language learning and teaching globally, this paper will focus upon Australia to gain a critical understanding of English language provision.

\section{Rationale}

The definition of language is not restricted to linguistic entities which are not the emphasis of this paper, because "language is a tool for acting in an interested and engaged way, on and in the material and social world" (Emmitt, Komesaroff, \& Pollock, 2006, p. 18) ${ }^{[1]}$. From the communicative perspective, the number of language learners is considerable, because for them "the limits of my language mean the limits of my world" (p. 3) ${ }^{[2]}$. On the part of language teachers, they are expected to develop a more explicit understanding and appreciation of language, which will help them have greater and more precise insights into their role in teaching-learning contexts (p. 3) [3]. From the above we can see that language acts as the common target between teachers and learners, and hence the corresponding educational sectors where languages are taught and learned are needed. The following report will revolve around English learning and teaching in the local and global contexts, demonstrating an insightful investigation into English language provision in Australia through a variety topics ranging from general purposes to specific programs, with the aim of achieving high levels of understanding and intercultural communication.

\section{Background}

In terms of the local context in Australia, it could be divided into historical, social and cultural aspects. The historical background of Australia makes English the mother language of Australians, and language learning and teaching within one's own country is a basic component of its education and daily lives, as well as for the maintenance and development of their own language. According to DIAC (n.d.) ${ }^{[4]}$, Australia is a country with all types of migrants from various parts of the world. This social factor makes English language learning and teaching a necessary way deal with the 
intercultural issues. In addition, a number of projects and data from DEEWR (n.d.) ${ }^{[5]}$ show the prosperous international education in Australia with increasing number of overseas students.

\section{English Language Provision in Australia}

The investigation starts from the understanding of the research objective, which is to gain a broad understanding of different contexts and purposes for English language teaching and learning globally, and a detailed critical understanding of English language provision in Australia. In the light of the research through internet, different sectors where English language is taught and learned in Australia will be presented in the following points covering purposes, programs, courses, providers, clients, credentials, approaches, assessments, regulations and funding sources.

ELICOS. It is Australia's English Language Intensive Courses for Overseas Students. Its program has been designed for students requiring English language training before commencing formal studies in Australia. However, its students are not restricted to this specific group, because these programs are open to everyone, including people on a tourist or visitor visa in Australia and not wanting to do any further study after completing their English classes. All new ELICOS colleges should undergo a national accreditation process called the National ELICOS Accreditation Scheme. The accreditation functions as a safeguard for students coming to Australia, because it requires all centres to comply with a set of standards such as qualified English teachers, accredited programs and small sized classes. On the part of tuition fees, they range from AUD \$250 per week to AUD\$350 per week for regular ELICOS courses, involving 25 hours of tuition per week. (ELICOS, n.d.) ${ }^{[6]}$

AMEP. The Adult Migrant English Program composed of migration and humanitarian programs, is funded by Australian government with two successful consortiums of providers, Australian Centre for Languages (ACL) led consortium and NSW Adult Migrant English Services (AMES) led consortium. It provides basic ESL tuition in the English language to help eligible adult migrants and refugees settle successfully in Australia. Eligible clients can study English for up to 510 hours or until they reach a functional level whichever occurs first. It should be pointed out that clients must register within three months of arriving in Australia and begin classes within one year. The AMEP teaching approaches consist of five types, direct method, structure based syllabus, situational English, learner centered and needs based approach, and competency based accredited approach, which will be practiced through teachers trained in teaching English to speakers of other languages and employed by local organizations called service providers. In terms of the contents, besides English language teaching, what is taught in AMEP includes several areas such as Australian society, culture and customs. In addition, it has a national accredited curriculum, offering the certificate in spoken and written English. (DIAC, n.d.) ${ }^{[7]}$

TAFE. It means Technical and Further Education, and five hundred TAFE campuses are located across Australia. Its courses are commonly designed for young people preparing for their first job, mature age people looking to train or retrain and people preparing for university studies. Students at TAFE could learn practical skills that are transferable to the workplace, because most TAFE courses are based on national competency standards set around industry training packages, which are designed to produce a nationally consistent curriculum and levels of training. During the process of learning, students are required to apply the corresponding skills in the workplace. In this sense, TAFE students possess a certain practical experience. With regard to the courses, there are currently six levels from Certificate I to IV in addition to Diploma and Advanced Diploma courses. Moreover, higher education courses such as Bachelor degrees, Graduate Certificates and Graduated Diplomas in selected fields of study are offered to a small extent. As far as TAFE ESOL course is concerned, it covers speaking and listening, reading and writing, vocabulary and punctuation and grammar at different levels. (Mature Study, 2007) ${ }^{[8]}$

LLNP. It refers to the Language, Literacy and Numeracy Program, which is managed by The Department of Education, Employment and Workplace Relations (DEEWR). It provides language, literacy and numeracy training for eligible clients who are referred to a Language, Literacy and Numeracy Program provided by referring agencies, currently Centrelink and Job Network 
Members. The program targets clients from non-English-speaking-backgrounds (NESB) only training at three different levels, initial, basic and advanced, including those seeking International English Language Testing System (IELTS) and Occupational English Test (OET) training as well as clients with literacy and/or numeracy training needs at two levels (basic and advanced) and clients needing specific advanced vocationally-oriented training. It should be clear that all clients must be of working age (generally 15 to 64 years) and be registered with Centrelink and not a full time student, satisfying eligibility criteria relating to benefit and visa status. The training is normally delivered face-to-face with a small proportion of distance-mode, and delivery of advanced vocationally-oriented training must meet vocationally specific requirements. (DEEWR, 2006) ${ }^{[9]}$

ACL. The Australian Centre for Languages, is the largest private provider of English language education in Australia and a leader in the development of English language teaching resources and support services. Annually ACL delivers high-quality language teaching to more than 18,000 students within Australia, and it also delivers English language training, resources and services to a rapidly growing number of individuals and organizations in the context of English as a global language. In detail, its education export focus is to conduct English language courses for international students; while its community and settlement focus is to deliver a significant portion of the Adult Migrant English Program (AMEP). ACL wins its high reputation because of the highly qualified and experienced teaching, curriculum development and management teams. In respect to the courses, ACLEnglish is a suite of 1,320 hours of online courses, resources and support services, and it can be used in the classroom or at a distance in a mixed approach. (ACL, 2005) ${ }^{[10]}$

AMES. Adult Multicultural Education Services, is Australia's largest provider of specialist, multicultural language, employment and settlement services. It provides an extensive range of adult education, training and employment programs to over 40,000 people every year. (AMES, n.d.) ${ }^{[1]}$

EA. English Australia, is the national association for accredited public and private English language colleges in Australia, promoting quality English language training and representing the interests of member colleges. (EA, n.d.) ${ }^{[12]}$

NEAS. The National ELT Accreditation Scheme Limited, is Australia's national accreditation scheme for English Language Teaching centers, aiming to establish and uphold high standards of service provision in English Language Teaching in Australia. NEAS maintains close relationship with Commonwealth and State government authorities, with frequent formal and informal consultations on matters affecting the quality of English Language Teaching in Australia. NEAS engages the services of a group of professionals in English Language Teaching to conduct assessments for accreditation and monitoring of institutions, and members of the NEAS assessment panel receive regular training on the accreditation system. (NEAS, n.d.) ${ }^{[13]}$

\section{Discussion}

The above presentation of findings indicates one clear advantage of English language provision in Australian in terms of quantities. On the other hand, it means that the programs and courses offered as well as the approaches and assessments meet the requirements of clients from different backgrounds. However, the critical understanding of the local contexts will be shown in the following points with specific examples.

The advantage of ELICOS is its openness to any clients, but it is also its disadvantage in regard to developing specific teaching materials and approaches. The idea of National ELICOS Accreditation Scheme is appreciated but the standards could be thought of as being subjective to some extent, because the standards are provided within the sector and need comparing with other sectors. The free charge of AMEP benefits the clients without question. Furthermore, its broad contents of English language teaching demonstrate the idea of intercultural language teaching which should be greatly practiced and improved. However, this approach to English language learning and teaching should be adjusted accordingly in accordance with the levels of target clients. It can not be denied that TAFE possesses the most obvious advantage in practical function, because TAFE graduates are acknowledged to have practical experiences. Nevertheless, the question lies in an example that how a TAFE graduate could be more competitive in the field of interpreting and 
translation compared with a master degree holder of the same major under the circumstance that both of them have the NATTI certificate.

The limitation of the research lies in the data which is restrictive and one sided, as they are gathered from the official websites which are subjective to some degree by means of presenting their own views and neglecting some disadvantages. In this sense, the research scope should be broadened, and the practical investigation is needed in order to produce an objective critique.

\section{Summary}

English language provision in Australia has made a lot of achievements, and a conclusion could be drawn that the future of English learning and teaching globally is bright. Meanwhile, it is worth noting that the intercultural consciousness in English language learning and teaching is well aware of and emphasized, which will have positive influences on communication. With a view to making the English language learning and teaching internationally efficient, TESOL methodologies need exploring across cultures consistently. Overall, as the practiser of English language learning and teaching, English language sectors in Australia as well as the world should take the responsibility to carry out the research for the sake of the language itself and high levels of understanding of the entire human race.

\section{References}

[1,2,3] Emmitt, M., Komesaroff, L., \& Pollock, J. (2006). Language and learning: An introduction for teaching. ( $4^{\text {th }}$ ed.). Melbourne: Oxford University Press.

[4] Migrants. (n.d.). DIAC. Retrieved April 16, 2015, from

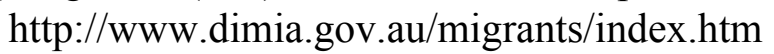

[5] International education. (n.d.). DEEWR. Retrieved April 16, 2015, from $\mathrm{http}: / /$ www.dest.gov.au/sectors/international_education/default $2 . \mathrm{htm}$

[6] What is ELICOS. (n.d.). ELICOS. Retrieved April 16, 2015, from http://www.elicos.com/about-elicos.php

[7] Learning English with the Adult Migrant English Program (AMEP). (n.d.). DIAC. Retrieved April 16, 2015, from http://www.immi.gov.au/living-in-australia/help-with-english/learnenglish/index.htm

[8] What is TAFE. (2007). Mature Study. Retrieved April 16, 2015, from http://www.unisanet.unisa.edu.au/maturestudy/EntryPathways/TAFE/whatisTAFE.asp

[9] About the Language, Literacy and Numeracy Program. (2006). DEEWR. Retrieved April 16, 2015, from http://www.llnp.deewr.gov.au/about_the_program.htm

[10] About ACL. (2005). ACL. Retrieved April 16, 2015, from http://www.acl.edu.au/about_acl.htm

[11] AMES vision: Full participation for all in a cohesive and diverse society. (n.d.). AMES. Retrieved April 16, 2015, from http://www.ames.net.au/about

[12] About EA. (n.d.). EA. Retrieved April 16, 2015, from http://www.englishaustralia.com.au/index.cgi? $\mathrm{E}=$ hsvalidator \&template=about $\& \mathrm{PT}=\mathrm{dd} \& \mathrm{Lev} 1$ $=$ pub_abea07\&Lev2=ea_intro07

[13] About NEAS. (n.d.). NEAS. Retrieved April 16, 2015, from http://www.neasaustralia.com/fst.html 